\title{
Time Correlation Analysis of the Microseismicity of the Low Eastern Flank of Mt. Etna Volcano (Italy)
}

\author{
S. Vinciguerra, ${ }^{1}$ V. LAtOrA ${ }^{2}$ and D. Vinciguerra ${ }^{2}$
}

\begin{abstract}
An analysis in terms of time correlation functions has been applied to the time distribution of microseismicity. We considered the single station detections $(M<2)$ recorded by each one of the four working stations of the network of the Osservatorio Sismologico di Protezione Civile, Acireale (Catania), located on the active faults systems (Timpe) of the low eastern flank of Mt. Etna. Information obtained on the time regularity of seismic crisis and on the time correlation between the activities recorded by different stations allowed a better understanding of the role of the two main structures. The Timpa di Santa Tecla is the most seismogenic structure in the area and probably played a role in the magma transfer process for the 1989 eruption. Modifications of the local stress field by actions of this feature may have produced gravitational instability along a second structural system (the Timpa di S. Leonardello) with a time delay of about 100 days. By contrast, magma penetration associated with the larger eruption of 1991-1993 had a deeper rise system and had no effect on local stress conditions, consequently there was no correlation between volcanism and seismicity.
\end{abstract}

Key words: Volcanic earthquakes, microseismicity, statistical analysis, Mt. Etna.

\section{Introduction}

The seismic activity of a region has a dependence on space and time which does not have a purely statistical nature, since it is in general the consequence of the evolution of a complex geodynamic pattern. If one takes into account only the microseismicity, i.e. low magnitude and very shallow earthquakes detected by only one station, it is of interest to study the regularities in the time series and to search for possible connections between the time evolution of the microseismic activities recorded at two different stations located within a distance of the order of some kilometres. We shall discuss in the following the seismic information obtained from the four stations of the Osservatorio Sismologico di Protezione Civile, Acireale (Catania). The stations are located on active fault systems (Timpe) of the low eastern flank of Mt. Etna Volcano. This area is affected both by earthquakes recorded at all the stations $(2 \leq M \leq 4)$ and by microevents $(M \leq 2)$ recorded only

\footnotetext{
${ }^{1}$ Istituto di Geologia e Geofisica, Università di Catania, I-95129 Catania, Italy.

${ }^{2}$ Dipartimento di Fisica, Università di Catania and INFN-LNS, I-95129 Catania, Italy. Fax: (095) 383023. E-mail: VINCIGUERRA@Ins.infn.it
} 
by the station near the relevant single fault system. In this work we shall study the single station detections recorded by the network. This analysis may yield information on the evolution of the local stress field and geodynamics. On the other hand one does not expect that possible regularities and correlations will be easily brought into evidence, due to the influence of statistical fluctuations. We shall undertake this problem by using the time correlation method (LEVITCH, 1971; KendALL and STUART, 1966), which will be outlined in the next section.

\section{The Time Correlation Method}

Let us call $n_{i}(d)$ the number of local earthquakes recorded by the station $i$ during the $d$-th time interval belonging to a series of $D$ intervals of an observation period. The total number of earthquakes recorded by the station and the corresponding average value will be $N_{i}=\Sigma_{d} n_{i}(d)$ and $m_{i}=N_{i} / D$, respectively. In the following we shall consider one-day long intervals, and an observation period of $D$ days.

If one takes into account the activities recorded by the same station at the day $d$ and at the day $d+\delta$, a time correlation function can be defined as (LEVITCH, 1971; Kendall and StUART, 1966)

$$
C_{i}(\delta)=\frac{\left\langle\left[n_{i}(d+\delta)-m_{i}\right]\left[n_{i}(d)-m_{i}\right]\right\rangle}{\left\langle\left[n_{i}(d)-m_{i}\right]^{2}\right\rangle}
$$

where the angular brackets indicate the average over all possible values of $d$. For symmetry reasons it is enough to consider $\delta \geq 0$. With the normalization in eq. (1) we have $-1 \leq C_{i}(\delta) \leq 1$; the quantity at the denominator represents essentially the mean-square deviation of $n_{i}(d)$ from the average value $m_{i}$. In fact the root-mean-square deviation is defined as $\sigma_{i}^{\exp }=\sqrt{1 /(D-1) \Sigma_{d}\left[n_{i}(d)-m_{i}\right]^{2}}=$ $\sqrt{D /(D-1)\left\langle\left[n_{i}(d)-m_{i}\right]^{2}\right\rangle}$. For $\delta>0$ and the contingency of no correlation in time between the seismic activities recorded at the days $d$ and $d+\delta$, the function $C_{i}(\delta)$ will be zero, or rather fluctuate around zero, for all values of $\delta$, since it is obtained as an average over products of uncorrelated positive and negative deviations from the mean value $m_{i}$. If instead the deviations are correlated for, say, $\Delta$ days, being mostly both positive (as in earthquake swarms) or both negative (as in long quiet periods), then $C_{i}(\delta)$ will receive only positive contributions for values of $\delta$ of the order of $\Delta$ days or less.

More quantitatively, assume $n_{i}(d)$ has a well-defined increase around the day $d_{g}$ which can be described by a Gaussian shape $\exp \left[-\left(d-d_{g}\right)^{2} / 2 \sigma_{d}^{2}\right]$, with the half width at half maximum $\Gamma_{d}$ of the peak given by $\Gamma_{d}=1.677 \sigma_{d}$. It can be verified analytically that the correlation function $C_{i}(\delta)$ also has a Gaussian contribution proportional to $\exp \left[-\delta^{2} / 2 \sigma_{\delta}^{2}\right]$, with $\sigma_{\delta}$ given by $\sigma_{\delta}=\sqrt{2 \sigma_{d}}$. One can then extract the half width at half maximum $\Gamma_{\delta}$ of the Gaussian contribution from the 
experimental correlation function, and use it to evaluate the correlation time of the seismic activity under the only assumption that the swarm has a Gaussian-like behavior in time. It eventuates in fact that $\Gamma_{d}=\Gamma_{\delta} / \sqrt{2}$. Care must however be taken to ensure the validity of any interpretation of $C_{i}(\delta)$. In fact, if the range $D$ of data is not much larger than the correlation width $\Gamma_{d}$ of the structures, then unphysical oscillations appear in the correlation function, giving rise to the socalled (HALl, 1964; HoGg and CRAIG, 1965) finite range of data (FRD) error. In practice, to minimize $F R D$ errors, $D$ has to be larger than a few tens of $\Gamma_{d}$ (HALL, 1964).

If we want to analyze structures of the size of $\Gamma_{d}$, the relative $F R D$ error $\Delta C_{i}(\delta) / C_{i}(\delta)$ we commit in solving structures of length $\Gamma_{d}$ with an observation period of $D$ days can be shown to be proportional to $\sqrt{2 \Gamma_{d} /(D-\delta)}$ (HALL, 1964; KENDALL and STUART, 1966).

The method can also be applied to the study of the time correlation between the activities detected by two different seismic stations. Let us consider two stations $i$ and $j$, whose activities are given by the two distributions $n_{i}(d)$ and $n_{j}(d)$, with mean values $m_{i}$ and $m_{j}$, respectively. If one compares the activities at the two stations with a constant time difference of $\delta$ days (now positive or negative values of $\delta$ have to be considered), a cross-correlation function can be defined for each value of $\delta$ as:

$$
X_{i j}(\delta)=\frac{\left\langle\left[n_{j}(d+\delta)-m_{j}\right]\left[n_{i}(d)-m_{i}\right]\right\rangle}{\left\langle\left[n_{j}(d)-m_{j}\right]^{2}\right\rangle^{1 / 2}\left\langle\left[n_{i}(d)-m_{i}\right]^{2}\right\rangle^{1 / 2}}
$$

where the angular brackets indicate the average over all possible values of $d$. The normalization constant $\left\langle\left[n_{j}(d)-m_{j}\right]^{2}\right\rangle^{1 / 2}\left\langle\left[n_{i}(d)-m_{i}\right]^{2}\right\rangle^{1 / 2}$ is such that $-1 \leq X_{i j} \leq 1$ for each value of $\delta$. In case of no correlation in time between the seismic activities recorded independently at the two stations, $X_{i j}(\delta)$ will oscillate around zero for all values of $\delta$, as is the case for $C(\delta)$ with $\delta>0$. If instead the two distributions are positively correlated, i.e. the deviations from the averages are mostly both positive or both negative for the two stations with a delay time of about $\delta_{\text {delay }}$ days, then $X_{i j}(\delta)$ will be constantly positive for values for $\delta$ near to $\delta_{\text {delay }}$.

\section{Area of Investigation}

The eastern flank of Mount Etna Volcano (Fig. 1) is affected by a seismic activity often consisting of earthquake swarms, originated by a rather complex stress field. This field has different origins, such as the regional tectonics (MCKENZIE, 1970; BARBERI et al., 1973; LENTINI, 1982), the uprising of the volcano magma (Murray and Guest, 1980; Cosentino et al., 1982; Murray and Guest, 1982; McGuire et al., 1990; BonaCCORso and DAvis, 1993; PATANÈ et al., 1994) and the instability of shallow crustal blocks, whose mobility is associated with gravitational effects (Borgia et al., 1990; PATANÈ et al., 1994). 
The structural framework of this area is given by faults evincing morphological evidence (Timpe) associated with the master regional trends and by fractures which, on the contrary, can be detected only from low magnitude earthquakes, due to their shallow focal volume. The accumulated stress is relatively low since it is released essentially through low magnitude $(1 \leq M \leq 4)$ earthquakes. The four stations we will consider in this paper are located near the two main structural systems of the low eastern flank of Mt. Etna Volcano: Santa Tecla fault (Timpa di Santa Tecla) and the San Leonardello fault systems (Timpa di San Leonardello) (Fig. 2). These structural systems are affected by events characterized by distensive and compressive (Montalto et al., 1995) focal mechanisms. In particular the Timpa di S. Tecla is affected by both deep and shallow foci which show a link with the tectonic forces interesting this area, while the Timpa di S. Leonardello is interested only by gravitational processes as indicated by the shallow foci location.

Within the above scenario, to better understand the stress evolution around eruptive episodes, it is of interest to study the time correlation of microseismicity $(M \leq 2)$.

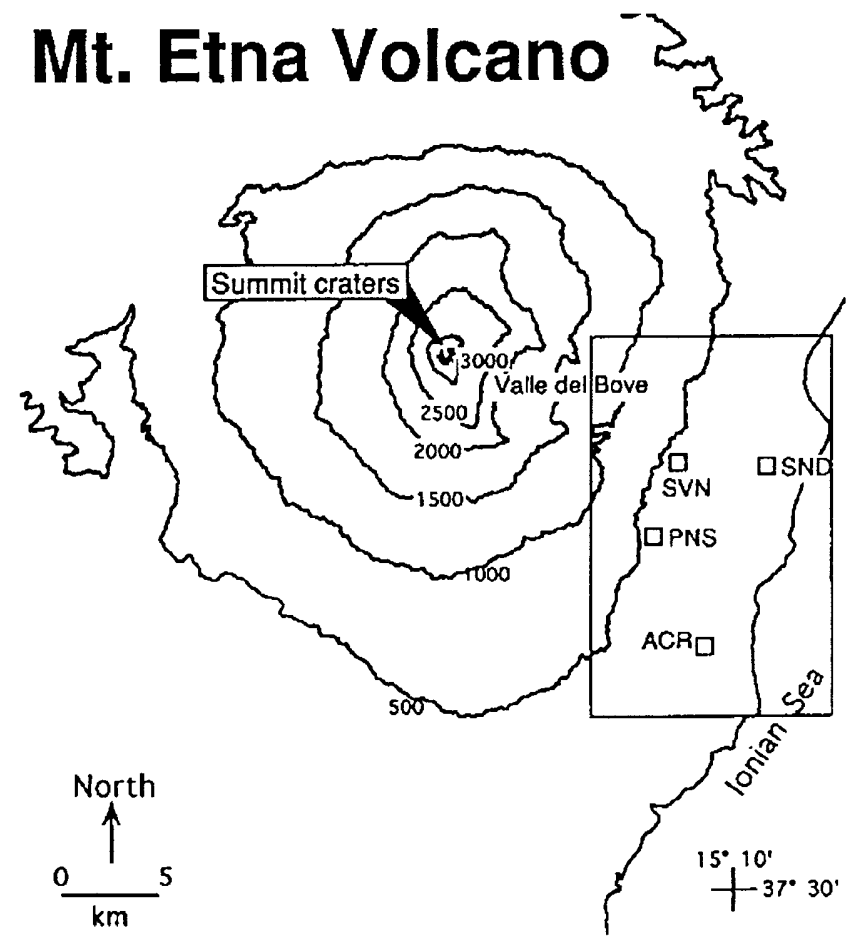

Figure 1

Map of Mount Etna Volcano. The box marks the region enlarged in Figure 2. 


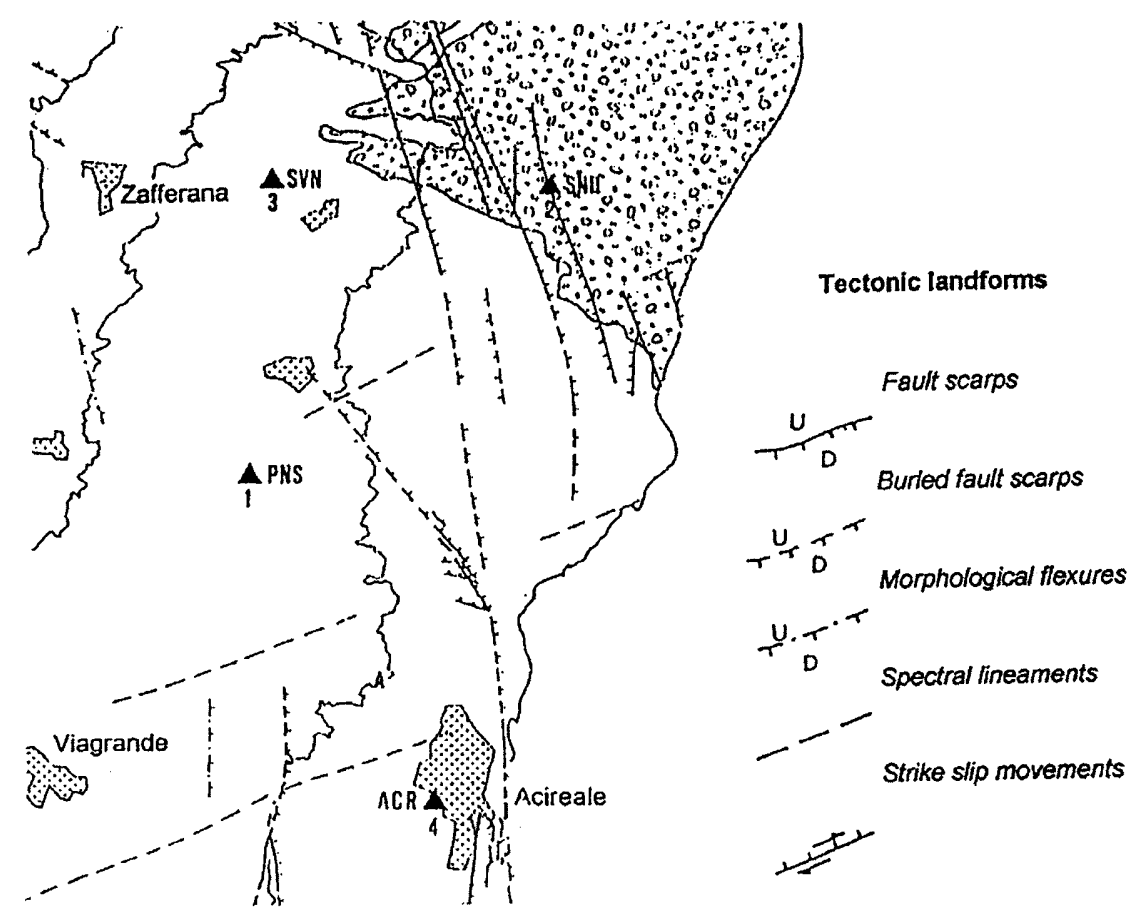

Figure 2

Map of the low eastern flank of Mount Etna Volcano. The principal faults and fractures of the region are indicated. The triangles refer to the location of the recording stations.

\section{Data Analysis}

The time correlation analysis was applied to microearthquakes recorded by the four stations located in the south-eastern flank of Mt. Etna (Fig. 2), named Pennisi (PNS), San Leonardello (SND), Santa Venerina (SVN) and Acireale (ACR). The network is operated by the Osservatorio Sismologico di Protezione Civile, Acireale. The data were taken between April, 22, 1989 and December, 31, $1994(D=2081 d)$. and they comprise both earthquakes with $2 \leq M \leq 4$ recorded at all the stations, and single station detection $(M \leq 2)$, i.e. microevents recorded only by the station near the relevant fault; we analysed the single station detections.

The number $N_{i}(i=1$ to 4$)$ of single station detections recorded by the four stations is reported in Table 1.

Table 1 also reports quantities relevant to the distribution in time of single station earthquakes. Here $m_{i}$ is the average number of earthquakes per day, $\sigma_{i}^{t h}={\sqrt{m_{i}}}_{i}$ is the root-mean-square deviation calculated for a Poisson distribution, $\sigma_{i}^{e x p}$ is the same quantity deduced from the data. 
Table 1

Quantities relevant to the distribution in time of local earthquakes detected by only one station (see text)

\begin{tabular}{llrccc}
\hline$i$ & Station & $N_{i}$ & $m_{i}$ & $\sigma_{i}^{\text {th }}$ & $\sigma_{i}^{\text {exp }}$ \\
\hline 1 & PNS & 263 & 0.267 & 0.516 & 0.837 \\
2 & SND & 204 & 0.207 & 0.455 & 0.592 \\
3 & SVN & 72 & 0.073 & 0.270 & 0.349 \\
4 & ACR & 55 & 0.056 & 0.237 & 0.255 \\
\hline
\end{tabular}

Figure 3 shows the number of single station earthquakes recorded daily at stations 1 (PNS), 2 (SND), 3 (SVN) to 4 (ACR). There is an evident clustering in time of the seismic activity for each station. This is supported by the fact that for all stations the standard deviation $\sigma_{i}^{\exp }$ of the activity turns out to be larger than $\sigma_{i}^{t h}$, i.e. the one predicted for a Poisson distribution (Table 1).

We calculated the autocorrelation coefficients $C_{i}(\delta)$ for each of the four stations and the cross-correlation coefficients $X_{i j}(\delta)$ for all the possible pairs of stations and the entire period considered (1989-1994). During this time two main eruptions occurred, starting respectively on September, 11, 1989 and December, 14,

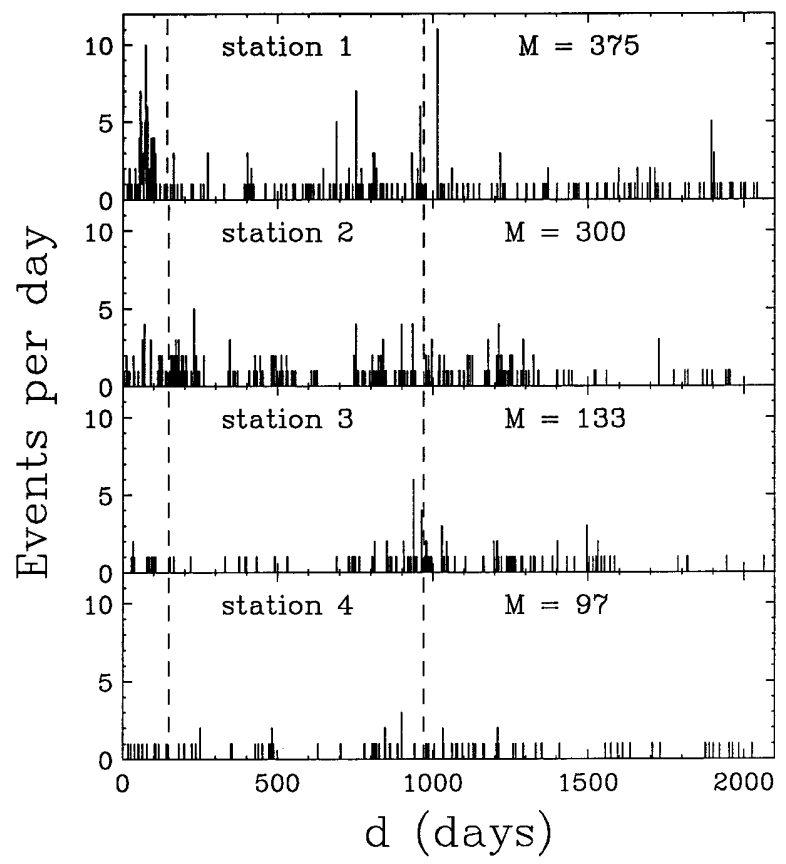

Figure 3

Number $n_{i}(d)$ of earthquakes per day detected by only one station. The labels 1 to 4 refer to the four stations mentioned in the text and reported in Figure 2. The limits of the 2081-day observation period are also reported. The vertical dotted lines mark the beginning of an eruption. 


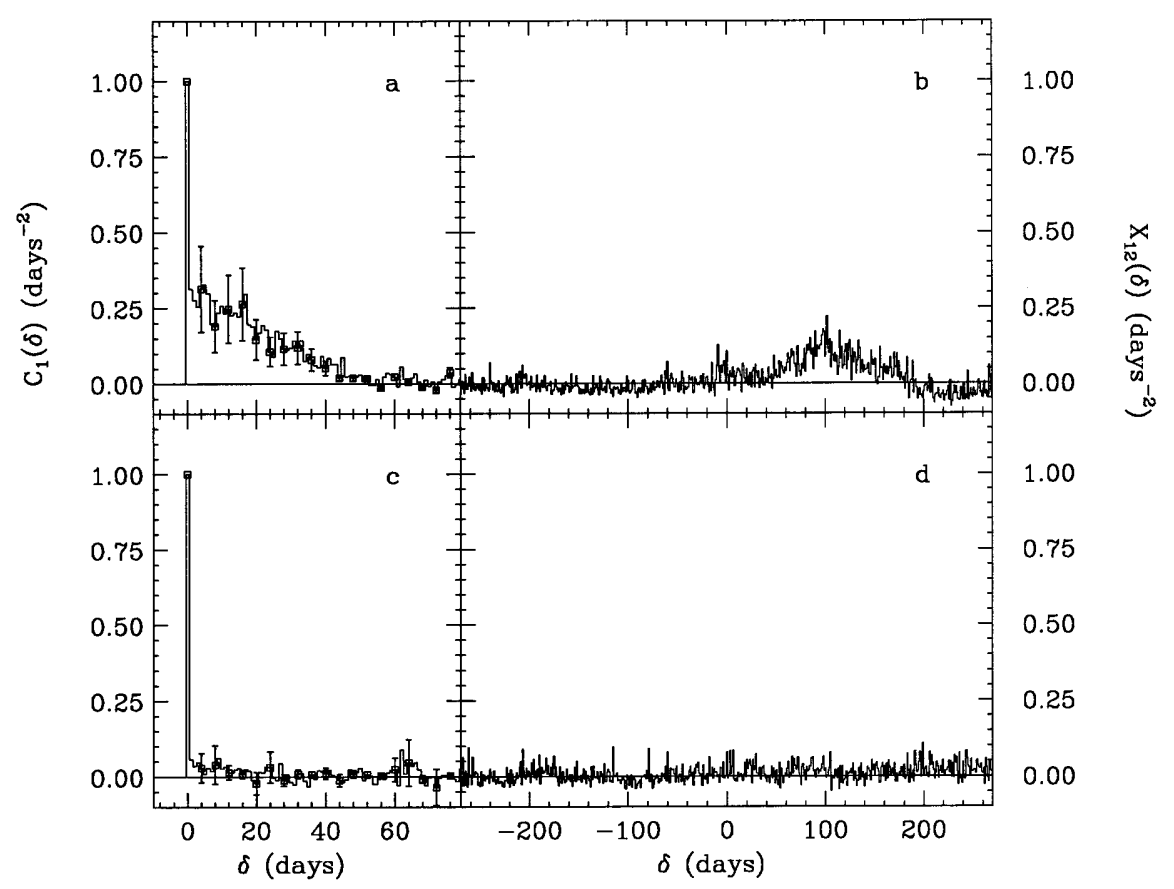

Figure 4

Auto correlation coefficients $C_{1}(\delta)$ and cross-correlation coefficients $X_{12}(\delta)$. a) and b) refer to the whole period $0-2081 d \mathrm{c}$ ) and d) to the period 201-2081 $d$ (see text).

1991. Actually all stations show a value of $C_{i}(\delta)$ consistent with zero for sufficiently large $\delta$, and positive for small values of $\delta$, but only station 1 has a peculiarly high value of correlation coefficients with a $T_{d} \approx 25 d$ as reported in Figure 4a. This behavior is substantially different from the background oscillations which are due to the finiteness of the observation period $D$ (see the error bars). Note that $D / T_{d} \approx 40$ so that the condition $D \gg \Gamma_{d}$ (see previous section) required to minimize the $F R D$ effects is satisfied here.

The calculated values of the cross-correlation coefficients $X_{13}(\delta), X_{14}(\delta), X_{23}(\delta)$, $X_{24}(\delta)$ and $X_{34}(\delta)$ are basically consistent with zero, thus indicating the absence of any significant time correlation between the activities recorded at the two involved stations. In Figure 4b we report the values of $X_{12}(\delta)$ for $-300 d<\delta<300 d$. In this case the situation is completely different; $X_{12}(\delta)$ shows a constantly positive behavior around $\delta \approx 100 d$. This indicates that a positive (negative) deviation from the average seismic activity at station 1 is followed by a positive (negative) deviation at station 2 with a delay $d_{\text {delay }} \approx 100 d$. Significance tests have been performed to check the validity of the $100 d$ lag correlations: the probability of obtaining a peak in the cross-correlation function higher than 0.15 with two 
uncorrelated signals is $14 \%$, while the probability of obtaining a peak higher than 0.2 is only $4 \%$ (TAYLOR, 1990 and references therein).

To verify a possible connection between the time evolution of the microseismicity and the volcanic activity, we recalculated the autocorrelation coefficients $C_{1}(\delta)$ and the cross-correlation coefficients $X_{12}(\delta)$ starting at $d=200$, i.e. shortly following the first eruption. The results are shown in Figures $4 \mathrm{c}$ and $4 \mathrm{~d}$, respectively. The disappearance of the two effects present in Figures $4 \mathrm{a}$ and $4 \mathrm{~b}$ namely the constantly positive value of the $C_{1}(\delta)$ and the peak at $\delta \approx 100 d$ in $X_{12}(\delta)$, is striking. Hence one is led to deduce that the time correlation indicated by the behavior of $X_{12}(\delta \approx 100 d)$ is not a systematic effect rather it must be related to the first main eruptive episode, which took place on September 11, $1989(d=$ $125)$ and continued until Oct. 9, $1989(d=153)$. Actually it is remarkable that $X_{12}(\delta)$ is determined by the contribution in the time distributions (Figure 3) given by the strong peaks at $d_{1} \approx 80 d$ for station 1 and at $d_{2} \approx 180 d$ for station 2 with a delay of about 100 days. The second main eruption which took place on $d=968 d$ (Dec. 14, 1991) and continued until $d=1441$ (Mar. 31, 1993) does not seem to be accompanied by a significant microearthquake arise occurrence.

\section{Discussions and Conclusions}

We analyzed by means of correlation function the microearthquake time distribution affecting the low eastern flank of Mt. Etna during 1989-1994 when two main eruptions occurred (Sep. 11, 1989-Oct. 9, 1989 and Dec. 14, 1991Mar. 31, 1993). We suggest that the inflation process affecting the volcano before the eruption onsets can induce on its surroundings detouchments along the structural lineaments originating microseismicity. In particular:

i) the main structure crossing the investigated region, i.e. the Timpa di Santa Tecla, is the most seismogenetic structure of the area, as the high number of earthquakes detected by station 1 shows. This is in line with the findings of previous papers (PATANE et al., 1994; Montalto et al., 1995). The value of the autocorrelation coefficients and $T_{d} \approx 25 d$ for station 1 suggest that Timpa di Santa Tecla plays an active role in the magma transfer processes.

ii) The action of the Timpa di Santa Tecla could give rise to significant modifications of the local stress field. The cross-correlation analysis points out that this modification of the stress would favour shallow gravitational instability, eventually involving with a time delay of about 100 days the Timpa di San Leonardello (downhill and northward with respect to Timpa di Santa Tecla), where station 2 is located. Such a movement would constitute sideward eastbound shift of unsupported rigid blocks upon shallow independent décollements (MONTALTO et al., 1995). 
iii) The disappearance of the correlations in $C_{1}(\delta)$ and $X_{12}(\delta)$ after $d=200$ implies that the microseismicity distribution connected with the second eruption has a different time evolution. This difference is in agreement with previous findings. In fact the 1989 eruption was characterized by the transfer of a relatively small volume of magma within the volcano edifice, which arose by means of lateral injections controlled by the local conditions of stress (MCGuire and Pullen, 1989). This fact implies that the local structural systems play a key role in the magma arise, inducing the occurrence of microseismic swarms. The evolution of the local stress field may well propagate along the local structural systems according to the findings of the present work.

The 1991-1993 eruption was the third largest since the 17th century. In such a case it is instead the deep arise system which is believed to control the magma penetration within the volcano edifice (FERRUCCI et al., 1992). The latter would have no significant relationships with the local stress conditions, explaining the observed absence of time correlation in the detected microseismicity.

The above considerations connected to models of the area under consideration illustrate the relevance of our findings. At the same time we think it is important to stress the possibilities offered by the time correlation method, in particular if it is applied to the data of a more extended recording network.

The authors are indebted to the Osservatorio Sismologico di Protezione Civile di Acireale (Catania) and particularly to S. Menza for the kind and skillful collaboration in data analysis. They also warmly thank G. Patané for useful suggestions in the geodynamical interpretation and A. Bonasera, M. Di Toro, M. Papa and A. Rapisarda for their fruitful discussions.

\section{REFERENCES}

Azzaro, R., Lo Giudice, E., and RasÀ, R. (1989), Note Macrosismiche e Considerazioni Sismotettoniche, In Attività Etna 1988, Monografie CNR IIV, pp. 40-56.

Barberi, F., Gasperini, P., Innocenti, F., and Villari, L. (1973), Volcanism in Southern Tyrrhenian Sea and its Geodynamic Implications, Geophys. Res. 78, 5221-5232.

Bonaccorso, A., and Davis, P. M. (1993), Dislocation Modelling of the 1989 Dyke Intrusion into the Flank of Mount Etna, Sicily, Geophys. Res. 98, 4261-4268.

Borgia, A., Burr, J., Montero, W., Morales, L. D., and Alvadaro, G. (1990), Fault Propagation Folds Induced by Gravitational and Slumping of the Central Costa Rica Volcanic Range: Implications for Large Terrestrial and Martian Volcanic Edifices, Geophys. Res. 95, 14357-14382.

Cosentino, M., Lombardo, G., Patane, G., Schick, R., and Sharp, A. D. L., Seismological researches in Mount Etna: State of art and recent trends. In Mount Etna Volcano (ed. Romano, R.) (Mem. Soc. Geol. It. 23, 1982) pp. 159-202.

Ferrucci, F., Gresta, S., Patanè, D., and Rasà, R. (1992), Inferences on the Magma Feeding System at Mt. Etna Volcano from Seismological, Structural and Volcanological Data, Atti XI Convegno GNGTS, Rome, 1, 455-460.

Gasperini, P., Gresta, S., and Mulargia, F. (1990), Statistical Analysis of Seismic and Eruptive Activities at Mt. Etna during 1978-1987, J. Volc. Geoth. Res. 40, 317-325. 
Hall, I. (1964), Finite Energy Range, and Modulation Effects in the Analysis of Cross Section Fluctuation Data, Phys. Lett. 10, 199-201.

Hogg, V., and Craig, L. D., Introduction to Mathematical Statistics (Macmillan, 1965).

Kendall, M. G., and Stuart, A., The Advanced Theory of Statistics, Vol. 2 (Charles Griffin Company, London 1966).

Lentini, F., The geology of the Mt. Etna basement. In Mount Etna Volcano (ed. Romano, R.) (Mem. Soc. Geol. It. 23, 1982) pp. 7-25.

Levitch, B. G., Theoretical Physics, Vol. 2: Statistical Physics (North Holland Publishing Company, Amsterdam 1971).

Lo Giudice, E., and RasȦ, R. (1992), Very Shallow Earthquakes and Brittle Deformation in Active Volcanic Areas: The Etnean Region as an Example, Tectonophys. 23(202), 1-12.

Luongo, G., Del Gaudio, C., Obrizzo, F., and Ricco, C. (1989), Movimenti Lenti del Suolo all'Etna mediante Livellazioni di Precisione, Boll. Gruppo Naz. Vulc., CNR 1989-91, 345-361.

McGuire, W. J., Pullen, A. D., and Saunders, S. J. (1990), Recent Dyke-induced Large-scale Block Movement at Mount Etna and Potential Slope Failure, Nature 343, 357-363.

McGuire, W. J., and Pullen, A. D. (1989), Location and Orientation of Eruptive Fissures and Feeder-dykes-induced at Mt. Etna; Influence of Gravitational and Regional Stress Regimes, J. Volc. Geoth. Res. 38, 343: 325-344.

McKenzie, D. P. (1970), The Plate Tectonics of the Mediterranean Region, Nature 226, 239-243.

Montalto, A., Vinciguerra, S., Menza, S., and Patane, G. (1995), Recent Seismicity of Mt. Etna: Implications for flank instability. In Volcano Instability on the Earth and Other Planets (McGuire W. J., Jones, A. P., and Newberg J., eds.) Geological Society Special Publication 110, 169-177.

Murray J. B., and Guest, J. E. (1980), Vertical Ground Deformations by Precise Levelling Techniques. In UK Research on Mount Etna, 1977-1979 (ed. The Royal Soc.), pp. 18-20.

Murray, J. B., and Guest, J. E. (1982), Vertical Ground Deformation on Mount Etna: 1975-1980, Geol. Soc. Am. Bull. 93, 1160-1175.

Patane, G., Gresta, S., and Imposa, S. (1984), Seismic Activity Preceding the 1983 Eruption of Mt. Etna, Bull. Volc. 74, 941-952.

Patanè, G., Menza, S., Imposa, S., and Di Stefano, G. (1990), The Etnean Earthquake of the January 29, 1989 - Macroseismic and Instrumental Characters Proceed. the 9 Meeting of the Gruppo Nazionale Geofisica della Terra Solida 57, vol. I.

Patanè, G., Montalto, A., Imposa, S., and Menza, S. (1994), The Role of Regional Tectonics, Magma Pressure and Gravitational Spreading in Earthquakes of the Eastern Sector of Mt. Etna Volcano, J. Volc. Geol. Res. 61, 253-266.

Riuscetti, M., and Di Stefano, R. (1971), Il Terremoto di Macchia (Catania), Boll. Geof. Teor. Appl. $13,51,150-164$.

Scarpa, R., Patanè, G., and Lombardo, G. (1983), Space-time Evolution of Seismic Activity at Mount Etna during 1974-1982, Ann. Geophys. 1(6), 451-462.

TAYLOR, J., Introduzione all'Analisi degli Errori (Zanichelli, Bologna 1990).

(Received June 23, 1995, accepted October 10, 1997) 